Umstand begründet, dass kohlensaurer Baryt und Strontian, mit vielem kohlensauren Kalk gegeglüht, viel leichter in kaustische Oxyde übergehen, als im reinen $\mathrm{Zustande.} \mathrm{Wird} \mathrm{ein} \mathrm{solches}$ Glühproduct mit kochendem Wasser behandelt, so nimmt dieses dann die ganze Menge des Baryt- und Strontianhydrates, dagegen nur einen unbedeutenden, von dem Volum des angewandten Lösungsmittels abhängigen Antheil des Kalkhydrates auf. Sind Alkalien reichlich vorbanden, so thut man gut, den wässerigen Auszug. des Glühproductes mit kohlensaurem Ammonik zu fällen und diesen Niederschlag spectralanalytisch zu untersuchen. (Ann. der Chem. u. Pharm. CXXIII. 255-261.) G.

\title{
Die Gegenwart des kohlensauren Kalks in dem Trinkwasser
}

wurde von Dupasquier in Lyon zur Erhaltung der Gesundheit für nothwendig erklärt. Grimaud de Caux bekämpft diese Behauptung und theilt zur Beweisführung folgenden Fall mit. Ein Familienvater, dessen Geschäfte ihn mehrere Jahre in Dieppe zurückhielten, konnte sich nur dadurch vor den Gesundheitsstörungen schïtzen, welche ihm der Gebrauch des kalkhaltigen Brunnenwassers dieser Stadt verursachte, dass er solches Wasser nur benutzte, nachdem es gekocht worden war. (Compt. rend. 13. Octbr. 1862.)

H. Ludwig.

\section{Veber die Wirkung von zweifach-kohlensaurem Ammoniak auf Magnesiasalze.}

Die gewöhnliche Annahme, dass Magnesia aus ihren Lösungen durch kohlensaures Ammoniak nur theilweise und bei Gegenwart einer hinreichenden Menge eines Ammoniaksalzes gar nicht gefällt werden kann, erklärt E. Divers für nicht richtig, da auf Zusatz einer Lösung von kohlensaurem Ammoniak zu einer Magnesia. lösung auch bei Gegenwart von viel Salmiak ein Niederschlag entsteht. In verdünnten Lösungen ist jedoch zur Bildung desselben ein grosser Ueberschuss von kohlensaurem Ammoniak erforderlich; dadurch wird aber auch in Lösungen, die nur 1/6000 Magnesia enthalten, ein Niederschlag hervorgerufen. Bei hinlänglichem Ueberschusse an kohlensaurem Ammoniak besteht der Nieder- 